\title{
A critique of the Law Commission report on injuries to unborn children and the proposed Congenital Disabilities (Civil Liability) Bill*
}

\author{
Ian Kennedy King's College, London and R G Edwards Cambridge
}

The authors are members of the British Association Committee on Social Concern and Biological Advances. Following earlier discussions of legal and social problems arising from certain medical advances, they undertook, independently, to examine the Law Commission's study.

We have examined the Law Commission's proposed Bill and the report on which it is based, and we conclude that they are inadequate in several important respects. First, the report fails to confront squarely what should be the central matter of concern, the fact that a child has been born disabled because of some event occurring before or during pregnancy and is in need of care and compensation. Second, the Bill, though it provides for certain legal actions to lie, is far too narrow both in concept and in scope. Third, serious legal and social problems are likely to arise if the Bill becomes law. Finally, the Bill represents a number of ad hoc decisions without any coherent structure either in legal reasoning or in social policy.

\section{Terms of reference for the Law Commission}

The Law Commission was asked to advise the Lord Chancellor 'what the nature and extent of civil liability for antenatal injury should be.'1 The terms of reference are limited. The brief would certainly have read better as 'legal provision for the needs of children born disabled'. This would have necessitated a much broader response than that provided by the proposed Bill. Nonetheless, the terms allowed room for considerable innovation. What is unfortunate, however, is the narrow, restrictive interpretation put upon those terms. It is as well to remember that the background of the referral of the issue to the Law Commission was the thalidomide tragedy and the difficulties of dealing with its aftermath by existing legal means. ${ }^{2}$ Rather than accept the invitation to innovate, the Law Commission regarded it as 'inevitable'3 that its enquiry should be conducted within the context of the present law of tort which provides that

\footnotetext{
*Cmnd. 5709.

${ }^{1}$ Paragraph $\mathrm{I}$ of the Report.

2Paragraph I of the Report.

${ }^{3}$ Paragraph 4 of the Report.
}

compensation shall be payable only on proof of fault or under the rules of strict liability. Serious doubts must immediately arise as to the relevance $\overrightarrow{\text { of }}$ the existing system of tort law - dominated by the concepts of fault, causation and blameworthiness to the needs of children born disabled. Nor can 9 be right to base the compensation of the disabled child on the unlikely chance that the defendant in the tort action under the Bill is a man of mears able, realistically, to pay compensation. Also, the draft Bill can only be helpful to those protected by its specific provisions and who are prepared to $g$ to law for redress. Determination to pursue a clai through the courts is an important assumption of the report and the Bill since the plaintiff child and its family must possess the necessary resources and not be disabled by distress. Further, the Ioan Commission had the opportunity to clarify ofte law as to the attribution of legal personality to. $g$ fetus but spurned it, so that legal inconsistenofies remain whereby, for example, a fetus may be 형 legal person for the purposes of the law of succession but not for the law of tort.

Perhaps our most important criticism is th because of the way the Law Commission interpreted its terms of reference an alternative system of compensating disabled children through a state? operated and state-funded scheme was not con sidered. The Pearson Committee has been set up t疋 report on the whole issue of compensation for death or personal injury (including antenatal injury) an is specifically considering the principle of a no-faule state compensation scheme. ${ }^{4}$ Such a scheme is in our opinion far more relevant to the adequate provision of help to children disabled during pregnancy or before conception. In these circum stances we think it would be wrong for Parliament to act on the recommendations of the Law Com? mission and pass into law the draft Bill which perpetuates the existing legal scheme governingu compensation. The proposed alternative approact to compensation is already potentially availables since a Ministry charged with responsibility for the disabled has now been established and coule attend to the alleviation of distress in a disabled child through the allocation of funds and services? Such a national institution could ensure tha

${ }^{4}$ See paragraph 2 of the Report. 
disabled children need not rely on the whims of fault liability within a few narrow contexts. Our recommendations for such an alternative system, which at the same time would also provide for an action in tort where such an action was deemed appropriate, are set out in the appendix.

\section{Causative link between damage in the womb and subsequent disability}

The principal concern for the scientist lies in the Law Commission's examination of the causative link between an event occurring while the fetus is in the womb (preconception damage is considered later) and subsequently disability at birth. The Law Commission's report is, by and large, accurate but doubts exist about the selectivity exercised in choosing examples. The arguments that animal experiments can prove a causal link between injury to the mother and disablement in the child must be accepted with caution. Chimpanzees and orangutans are closest to man, but they are in short supply and too expensive for extensive experimentation. Variations are possible between other animals and human beings. With drugs, factors such as dosage and time of administration are important, and although causal relationships can be demonstrated for certain classes of chemically induced injuries to the fetus, such as virilization brought on by the use of progestogens, the exceptions are far more numerous than the examples for which effective legislation can be drafted. The complex legislation proposed to provide redress for such injuries would probably be ineffective anyway, insofar as it is difficult or impossible to foresee the ramifications of the use of some drugs (as shown by the eruption of vaginal cancer in the adult offspring of women given stilboestrol when pregnant), and for most disabled children it is simply impossible to test and ascribe the cause of injury. A further difficulty is that many drugs have a minimal effect, and so many substances can be called 'drugs' that, short of putting a woman on a diet of water(!), the ordinary risks of daily living must be accepted.

\section{Trauma at birth and disablement}

The other causes of fetal injury discussed by the Commission also raise doubts about the relevance of the proposed Bill. There are remarkably few examples of a clear link between traumatic incidents and children disabled at birth, yet trauma is included in the Commission's report. Injuries during birth, abortifacients, irradiation and disease are clearly relevant, but they raise other difficulties. The incidence of disablement caused by irradiation must be very low, for example, and the chance of a child suffering injury because of oxygen deprivation as the mother dies during birth, even if valid, does not represent a significant class of injury. Diseases such as German measles or venereal disease are much more important in terms of stress caused by disablement through an antenatal event and raise wide social questions, yet they are largely excluded from the Bill.

Our objection here is the fact that some causative links are identifiable and therefore relevant for the purposes of the proposed Bill, does not, in our opinion, justify the Law Commission in basing compensation entirely on the principles of causation and blameworthiness. Besides opening the door to scientific controversy, such a response is unlikely to further, and indeed may well be irrelevant to, the welfare of most children born with disabilities.

\section{Professional negligence}

A further anomaly affecting the welfare of the disabled child appears in the Bill's singling out for special consideration the question of professional negligence. ${ }^{5}$ The basic legal structure adopted in the Bill is that once a person can be shown to be liable in tort to the mother he is further liable ipso facto, without more, to any child who is subsequently born disabled if the disablement can be traced to his breach of duty to the mother. The liability to the child is thus derivative or parasitic, depending as it does on a previous breach of duty to the mother, but strict in that it does not call for any knowledge or foresight on the part of the defendant that the woman was pregnant. (We are not dealing here with preconceptual injury to a parent. This is considered later.) Thus, the ordinary citizen can avoid the risk of future liability to a child only by assuming - somewhat unrealistically that every woman from 12 years to 50 years is pregnant and at risk. Otherwise he finds himself liable strictly to the child disabled through any casual act of inadvertence amounting to negligence or other tortious conduct to the mother, and this is so, regardless of whether he knew or ought to have known either that the mother was pregnant or that his conduct posed a threat to a potential child.

The liability of the doctor or other professional appears at first sight to rest on the same grounds, namely, that the child to maintain an action must first show a breach of duty to the mother. The Bill provides, however, that if reasonable care is taken towards the mother - having regard to then received professional opinion - no liability is incurred if a child is subsequently born disabled even if the disablement is a consequence of that care and treatment. The standards of liability are thus not the same, for what this means is that to be liable the professional in treating the mother must, unlike the ordinary man, actually know or be careless in not knowing that his conduct will affect a fetus adversely. Indeed his treatment of a mother

${ }^{5}$ Section $\mathrm{I}(5)$ of the proposed Bill and the notes thereon. 
can only be in breach of duty to her in this context and thus serve as a basis for a future action by the child if he knew or ought to have known that such a breach would adversely affect the child. It is our view that this reasoning can be extended by analogy so as to be available to, for example, the Committee on the Safety of Medicines and, far more important, the pharmaceutical industry. The result is that neither a doctor, nor the Committee nor a pharmaceutical firm can, if acting in good faith, be made liable under the Bill if a drug which has only appeared on the market after extensive testing is administered to a mother and proves to have teratogenic properties at a later date. Thus, although the administration of such drugs may well be the single most likely source of fetal injury, liability for such injury will only follow in the rare circumstance that there has been some demonstrable breach of duty: for example, appropriate animal experiments have not been carried out or safety requirements not adhered to or there has been some manifest act of incompetence. Though this result may be justifiable in a system based on fault, its consequence is to leave a child who has been disabled because of an antenatal event induced by drugs without redress against those who are potentially the greatest source of risk and who may even be manufacturing or prescribing a particular drug specifically for pregnant women and without any alternative source of compensation. This would mean, incidentally, in our view, that if a new disaster on the pattern of the thalidomide incident occurred there would be no redress for the disabled children under the Bill as no breach of any legal duty to the mother could be pointed to, given the then existing state of knowledge, on which to ground the child's action. There can be no doubt therefore that in this regard the Bill misses the mark and could create serious problems both in legal actions and social practices.

\section{Applying the principles of civil liability - only to the mother}

We are of the view that the legal reasoning on which the Law Commission bases its Bill is open to question. Although the report speaks of applying the ordinary principles of civil liability, what the Bill does in fact is to apply these only vis-à-vis the mother. As we have seen, the duty, breach of which will give rise to liability at the suit of the child, is owed only to the mother. This is a departure from the ordinary principles of civil liability, particularly as regards the tort of negligence which the Law Commission recognizes as the most likely ground for liability. For negligence is based on the fault of a defendant in a context where he should have foreseen harm to the plaintiff. But, under the Bill, the plaintiff is the child who at the time of the careless act may well not have been foreseen. The method by which the Law Commission chooses avoid this anomaly is by the wholly unreal, and, we think, unjust in the context of fault liability, fictiog that every person foresees a fetus lurking in the womb of every women of childbearing age. This approach derives from the policy adopted by $t$ Law Commission of identifying the child legatity with the mother, rather than adopting othee, alternative legel approaches which we shall refer below. But this approach has a high price. Its log compels the Law Commission to provide in the B that, since the fetus is identified legally with the mother and liability to it is based on liability to the mother, defences available against the mother are equally available against the child. Thus, if the mother has herself been careless and has contributegl to the fetal injury, her contributory negligence w91 count against the child and its damages will $\overrightarrow{b e}$ reduced accordingly. More important still, if liability to the mother has been limited or excluded by contract or otherwise, then liability to the chigd is equally excluded. This may be good logic but it is utterly self-defeating in a Bill which purports 8 make provision for a child born disabled.

\section{Alternatives eschewed by the Law Commission}

ATtRIBUTING LEgal PERSONALITY TO THE FETUS $\vec{\vartheta}$ An alternative eschewed by the Law Commissiofi, though embraced for example in all the jurisdictiong of the United States of America, is to attríbutse legal personality to the fetus so that a duty can owed to it and if injured it may, if born alive, bring an action as being at the time of injury a perse capable of having legal rights. ${ }^{6}$ Admittedly, there are possible complications in this approach in thăt if a fetus is to have legal personality the practice of lawful abortion may seem challenged. This problew can, however, be avoided in a number of ways, one of which is simply to prescribe that the right bring an action exists and crystallizes only if and when the fetus is born alive. Arguments about abortion are not raised, therefore, since rights abe maintainable only at birth and, as The Times pert it, 'no birth, no rights'.? Our view is that thes approach would at least have produced a more fair and coherent set of principles, provided the proble of the disabled child was to be treated by recourse to the traditional legal action.

\section{CONCEPTS OF INJURY AND DAMAGE}

Another alternative approch both Australian and Canadian courts and, as in USA, development has occurred without the nesed

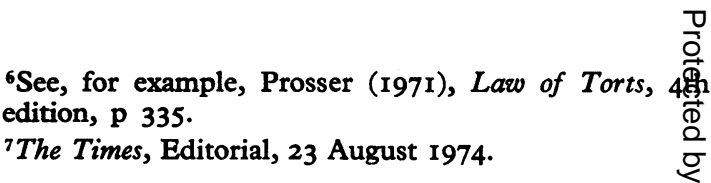


for legislation. 8 It proceeds on the basis that a defendant is liable to a child born alive and disabled if he could foresee the existence of the child while it was a fetus and if he acted in breach of the duty to behave with all due care towards such a foreseeable fetus. Instead of attributing legal personality, the courts have separated the concepts of injury and damage. The injury occurs to the fetus while in the womb. The damage is suffered and the cause of action accrues only when the child is born alive with a disablement caused by the injury. This again, we suggest, is preferable to the approach adopted by the Law Commission.

\section{The legal liability of the father in all circumstances}

A further inconsistency, and an example of the ad hoc thinking which pervades the report, appears in the decision that a mother may not, subject to one exception, be held liable to her child but a father can be held liable in all circumstances. ${ }^{9}$ Thus if a child is born disabled because either parent has had venereal disease, if it is the father he may be liable and compensation recoverable; if the mother there is no liability and no compensation. Though we appreciate that the reasons given for exempting the mother from liability are strong, we are of the view that they extend equally strongly to the father, particularly if the parents are married. Furthermore, if the parents are married, talk of damages being awarded to a child against its father is both meaningless and objectionable. Insurance cover taken out by the father will surely be rare and may well be too expensive if it is to cover every possible mishap to the mother. In its absence, family resources would not be altered by such a judgment. The family cake would still be the same and could only be divided as it had been in the past. To hold a father liable will not effect any real compensation for the disabled child. Moreover, considerable psychological harm could be inflicted on father and child alike since an already disadvantaged child will grow up in a home soured by litigation and court orders for damages. Interestingly, the only circumstance in which the mother can be liable is where her negligent driving of a car results in fetal injury and subsequent disability to her child. Not only is the scientific basis for this exception extremely questionable but it also illustrates further the Law Commission's ad hoc approach since it is the one circumstance in which it can be guaranteed that an insurance company will be standing behind the mother to pick up the bill for damages.

The possible liability of the father gives rise to a

${ }^{8}$ See, for example, Watts v Rama (1972). VR, 353, and Duval v Seguin, 26, DLR, 3rd, 418.

'Section $I(I)$ and the notes thereon. For the exception as regards the mother, see section 2 and the notes thereon. further criticism. Since there are no grounds for liability if the fetus dies before birth, a father's fear of possible liability could result in his encouragement, implicit or explicit, of the mother to abort the potentially damaged fetus in order to avoid the distressing possibility of being sued by his own disabled child. The Bill may, in other words, encourage the taking of fetal life, and to that extent it is both morally and socially indefensible.

\section{Legal rights of the newly born}

In this context a critical provision appearing in the Bill is that concerning the legal rights of the very newly born. The Bill provides ${ }^{10}$ that a baby must live for at least 48 hours before compensation for loss of expectation of life may be recovered by the parents. The basis of such compensation is that it is awarded to the personal representatives of the deceased who bring the action as if it were being brought by the deceased. It is, in other words, compensation which depends on the deceased having had a right of action. Moreover, in the case of a newborn baby damages for loss of expectation of life would be the only sizeable sum awarded. What the Bill does therefore is withhold the right of action for disability from a child until it has lived 48 hours. Withholding legal rights from any newborn child for 48 hours is surely too serious a matter to be dealt with in the supplementary provisions of a Bill on fetal injury. The proposal could encourage attempts to keep a fetus alive for 48 hours or longer just to satisfy technical requirements concerning personality and the right to take legal action, and thereby the Bill could encourage improper medical counsel. Infanticide might even be encouraged, in that a father may wish to avoid the legal implications of the Bill. Problems could arise over premature delivery, especially of a disabled child, and attempts to keep a premature baby alive could well be misconstrued. The time of 'birth' under these circumstances could also pose problems, and so could injuries preventing breathing at birth, which would presumably not involve liability under the Bill.

There is something unsatisfactory both from a logical and a scientific point of view in a Bill which denies an action to a child born at full term who dies within 36 hours of birth and allows an action to a child born prematurely who lives more than 48 hours but dies before reaching full term. Furthermore, it is possible to foresee situations in which a doctor who is negligent in delivering a child - in that while the mother suffers no harm the child, for example, encounters difficulty in breathing which could be fatal - may be tempted to let the child die before it has lived 48 hours and thus avoid liability under the Bill.

${ }^{10}$ Section 3(2). 


\section{Disability to a fetus caused by injury before conception}

We also entertain doubts about the provision in the Bill concerning disability to a fetus caused by injury to one parent or to both of them before its conception. Although liability is contemplated, the Bill provides that a defendant will not be liable to a child born disabled if the risk of the child being born disabled because of the defendant's tortious act was known to the parents before conception occurred.11 Again, the principle of identification of the fetus with the mother produces a result in which the disabled child is fixed with the knowledge of the parent and thereby goes without compensation. Thus, should potential parents ignore medical advice not to have a child because of some prior injury or they are unable for whatever reason to prevent conception, a disabled child will be left without redress - assuming it was not the father who caused the injury, since, as has been seen, he can be liable to the child. An overwhelming burden is placed on such a married couple to avoid pregnancy. The assumption is made that pregnancy is in fact avoidable in all circumstances, so that a child conceived in such circumstances because of a failure in contraception despite the efforts of the parents must go without recourse to compensation.

The notion of injury before conception having a causative link with subsequent disability itself raises many questions. Recessive mutations would not be expressed in the first generation yet the second generation is specifically excluded from rights under the Bill. Proof of causal links between agents acting on gametes or their precursors and subsequent effects in the child will be almost unobtainable. Lack of knowledge of some disorders, for example of the origin of certain forms of chromosomal imbalance in children, could lead to claims and judgments based on the flimsiest of evidence. Of great potential concern is the situation where medical interference is necessary to establish a pregnancy, for example, AID, fertilization in vitro, or the induction of ovulation. Such treatments could be withheld from patients if doctors became alarmed over the lack of adequate guidelines as to their legal position and responsibility.

\section{Conclusions}

In conclusion, the proposed Bill, though apparently innovative and internally coherent, is narrow and arbitrary. Even within its provisions are the seeds of doubt and disquiet raising difficult legal and social problems. More important, it will in no way satisfy the needs of most disabled children. Further, it suffers from the evils of at the same time inviting litigation from those able to pursue a case whereby parades of experts would be able in all conscience

${ }^{11}$ Section I(4). to hold differing views on the causation of particular disability and also constituting a disincentive to litigation to the more sensitive and less well off for the same reasons. Though alleged based on fault, the true basis of liability is strict as regards the child regardless of whether it w $\overrightarrow{\bar{a}}$ possible in the circumstances to foresee its existenee. The Bill should not be considered by Parliamet until the Pearson Committee has reported. The la obviously has its share of arbitrary decisione, sometimes on sensitive topics, and the Law Cons mission has found after its extensive enquiries that such arbitrariness obviously applies to man aspects of the law relating to fetal injury and subsequent disability in the child. Equally it $\$$ obvious that care must be taken not to add furthor complexities to a problem which is already complic $\overline{\mathrm{A}}$ ted enough by enacting into law a Bill such as this unless overwhelming reasons can be advanced in its favour, such as, for example, that it redounds to the benefit of all disabled children. This the Law Commission's Bill clearly fails to achieve. The present proposals are too limited. Only a sm代 minority of children could benefit from them and then only after difficult legal battles, while otheBs with identical disabilities could receive no compens tion at all.

\section{Appendix}

An alternative system for compensation $f$ disabled children

An alternative system should be based on the demands of social justice. The overriding priority must be the provision of compensation for all disabled children within the means available. two-tiered, fault/no-fault system could provide for such compensation. Provision should be made, with relatively few adjustments to existing administrative machinery, by establishing a system बैf state-provided compensation for any disablę child. A precedent exists in methods used identify and register chronically disabled persoms by local authorities. Any legislation would have to be accompanied by the establishment of adequare techniques for the monitoring and registering $\overline{\bar{p}}$ disabled children.

Should local authorities undertake the administra tion of such a scheme, parents would hold the compensation on trust for the disabled child Remedies to control and, where necessary, sanction the possible misuse of funds by parents would Fe needed. It could be argued that the promise of compensation may encourage parents to keep alive a disabled child when they might otherwise have avoided the extraordinary medical care which the may involve and this must be considered by the legislators. However, any suggestion which migfir 
encourage potential life cannot normally be open to criticism. For there is no doubt that the factor of compensation would be only one among many highly personal considerations taken into account by parents when a severely disabled child is born.

A scheme for compensation based purely on the no-fault principle would excuse people from responsibility for the consequences of their actions in circumstances where it was deemed wrong that they should be so excused. Thus, in any legislation it would be necessary to provide for those cases where fault could be proven and it was judged proper to expose the person at fault to liability. A right of action under such legislation should reside in the State, with the support of such bodies as the
Committee on the Safety of Medicines and leave undisturbed the issue of compensation to the disabled child which would be automatic. Details concerning the potential recipient of monies paid by a defendant would have to be determined. In order to prevent possible inequities, for example, where one disabled child might receive compensation from both the State and a defendant and another receive money only from the State, any money recovered should not be paid directly by a defendant to the disabled child. Instead, in the instances where the legislation authorizes the State to proceed against a particular defendant the State should be enabled to recover from the defendant a measure of the compensation paid to the child. 